116

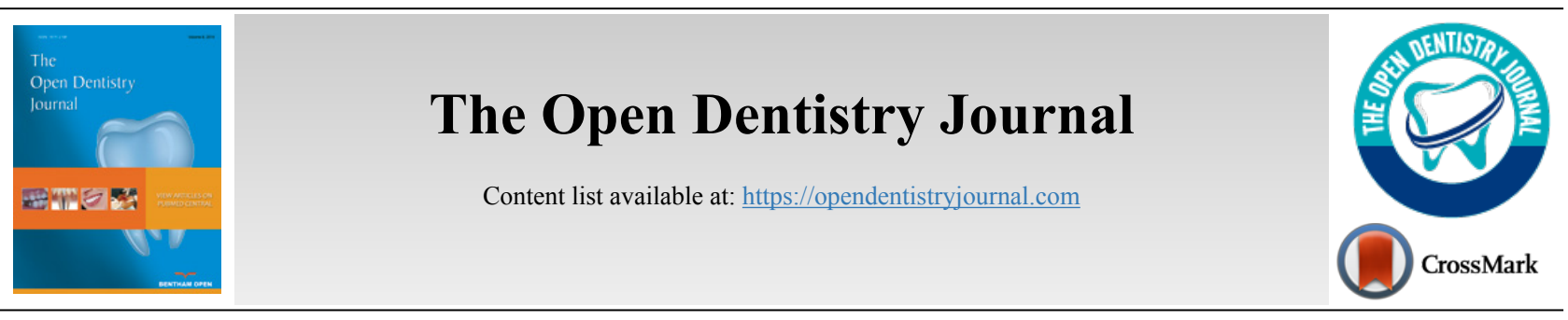

CASE REPORT

\title{
Orthognathic Surgery Combined with Glossectomy and Mandibular Constriction: A Case Report
}

Nilton Pires de Araujo Filho ${ }^{1}$, Thiago Leonardo Rios ${ }^{1}$, Everton Jose da Silva ${ }^{2}$, Thiago Iafelice dos Santos ${ }^{1,2}$, Andre Luis Fernandes da Silva ${ }^{1,2}$ and Alexandre Meireles Borba ${ }^{1,2, *}$

${ }^{1}$ Department of Oral and Maxillofacial Surgery, General Hospital of Cuiaba, Cuiaba, Brazil

${ }^{2}$ Research Program on Integrated Dental Sciences, Faculty of Dentistry, University of Cuiaba - UNIC, Cuiaba, Brazil

\begin{abstract}
:
Background:

Conventional orthognathic surgery can become challenging when multiple goals such as correction of transverse and anteroposterior discrepancies of the dental arches are aimed. Thus, additional procedures such as midline mandible osteotomy for mandibular constriction and tongue reduction due to true macroglossia may be alternatives to a more functional and aesthetical outcome.

\section{Case Report:}

A treatment of a 35-year-old female patient with Class III sagittal skeletal pattern marked by an increased angle facial profile, maxillary retrusion, vertical maxillary deficiency, and mandibular protrusion, a Class III malocclusion associated to an edentulous maxilla, partially dentate mandible, transverse mandibular excess and true macroglossia. With an Index of Orthognathic Functional Treatment Need (IOFTN) grade 5, the patient underwent bimaxillary orthognathic surgery, mandible constriction and partial glossectomy. After about a year of follow-up, the patient demonstrated skeletal stability for the orthognathic procedures as well preservation of tongue function.

\section{Conclusion:}

The combination of the techniques performed was effective in the treatment of the multifaceted deformities, providing satisfactory function, harmonious facial aspect and enabling effective prosthetic rehabilitation to the patient.
\end{abstract}

Keywords: Orthognathic surgery, Mandibular constriction, Macroglossia, Partial glossectomy, Mandible osteotomy, Class III malocclusion.

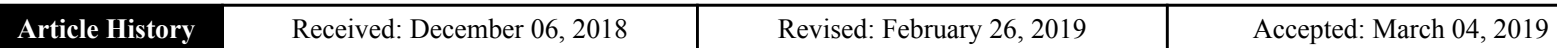

\section{INTRODUCTION}

Orthognathic surgery has the objective of correcting skeletal deformities of congenital or acquired congenital origin, repositioning the bony bases that support the upper and lower teeth (maxilla and mandible), seeking facial harmony, functional occlusion, the health of orofacial structures, aesthetics and stability [1]. Among the various combinations of dentofacial deformities, transverse discrepancies are more common to the maxilla while rarely affect the mandible [2]. These changes due to hypodevelopment are commonly treated through osteogenic distraction or graft osteotomies while mandibular hyperdevelopment cases are treated with mandibular constriction and median osteotomy.

\footnotetext{
* Address correspondence to this author at the Program on Integrated Dental Sciences, Faculty of Dentistry, University of Cuiaba - UNIC, Avenida Manoel José de Arruda 3100, Jardim Europa, Cuiabá - MT, CEP 78065-900, Brazil; Tel: 55-065-3363-1139; E-mail: aleborba80@hotmail.com
}

Medial mandibular osteotomies used to be performed in a linear vertical fashion, which sometimes resulted in periodontal defect or poor bone healing due to poor bone contact. Clayman and Adams described the technique of medial step osteotomy, which provides a greater area of bone contact, more stability, and less chance of resulting in periodontal defects as it does not cause a long sagittal or vertical defect in the mandibular symphysis [3, 4].

Macroglossia is frequently associated with transverse excess of the mandible, being a change of multiple etiologies, classified as true or relative, congenital or acquired. This variation can cause the individual several problems in the orofacial growth, such as mandibular hyperdevelopment, poor positioning of the teeth in the jaws, glossitis, and a decrease in airway space, among others. These anatomical problems, in most cases, generate functional problems, such as dysphonia, dysphagia, malocclusion, and even obstructive sleep apnea 


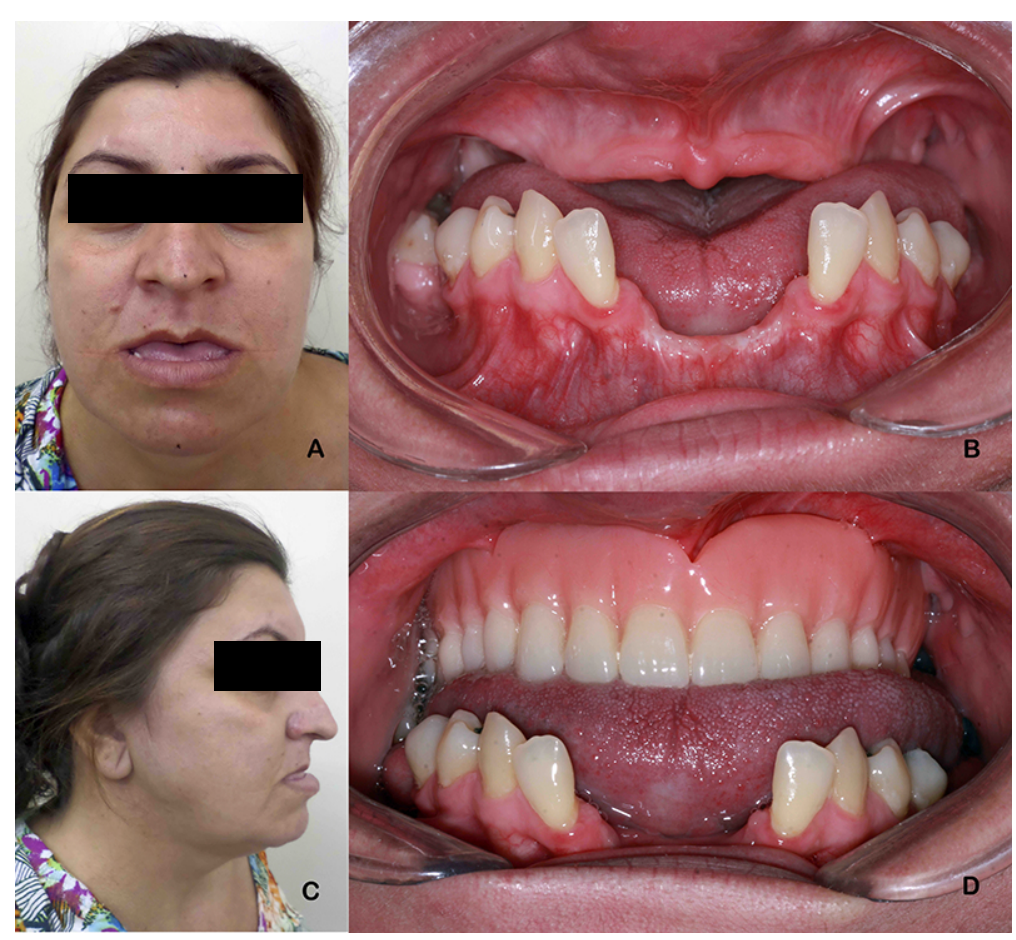

Fig. (1). Patient in her initial presentation, with remarks to the open bite at rest, noticeable maxillary deficiency, tongue protrusion and lip incompetence: A - Frontal facial view; B - Frontal intraoral view; C - Lateral facial view; D - Frontal intraoral view with upper jaw prosthesis.

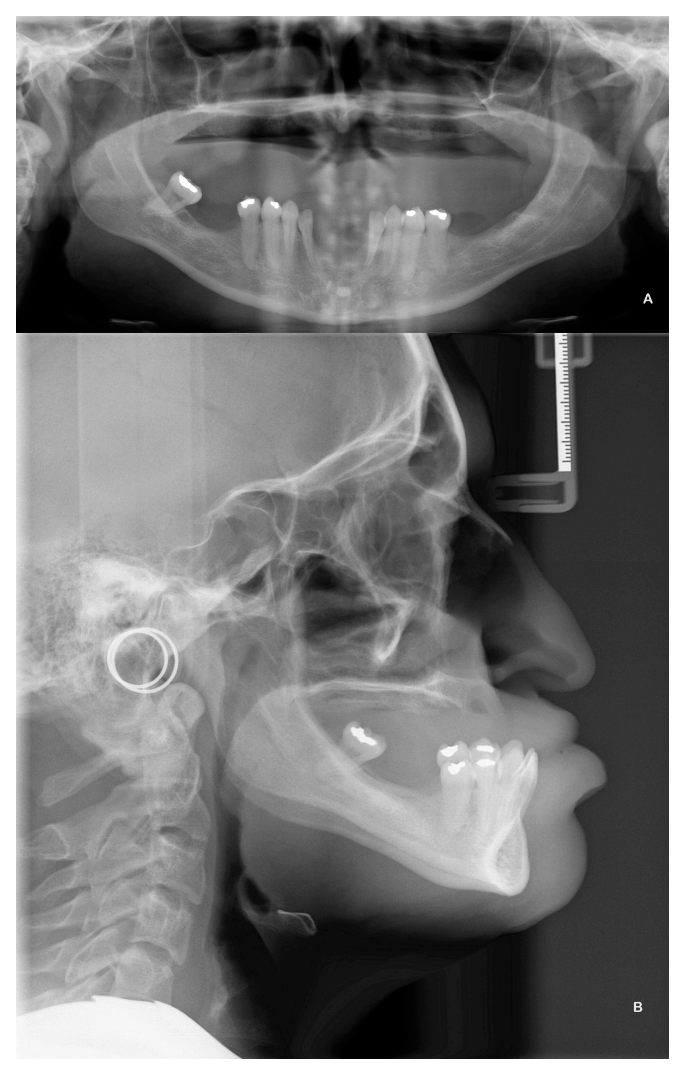

Fig. (2). Panoramic radiography (A) and lateral facial radiography (B) displaying an increased angle facial profile, maxillary retrusion, vertical maxillary deficiency and mandibular protrusion.

syndrome [5]. Diagnosis is an extremely important step; it will define the best treatment and the most indicated technique. Although it is not a frequently performed procedure, partial glossectomy has been shown to be effective in cases of true macroglossia, significantly reducing tongue size whilst preserving its function [6].

The combination of surgical procedures for the treatment of macroglossia and dentofacial skeletal deformities has been described in the literature. Wolford and Cottrell reported three treatment sequences, combining partial glossectomy with orthognathic surgery, highlighting advantages as ortho-surgical stability, increase in airway permeability, and intraoperative feasibility [6]. However, a combination of the aforementioned procedures in a detailed and illustrated report has not been published. The case report hereby present intends to contribute to such understanding.

\section{CASE REPORT}

A Caucasian 35-year-old female patient presented with complaints of significant diastema of lower anterior teeth, edentulism of the maxilla, and loss of vertical dimension of occlusion. Physical examination revealed a class III skeletal relationship marked by an increased angle facial profile, maxillary retrusion, vertical maxillary deficiency, and mandibular protrusion $[7,8]$. Intra-oral assessment was defined by a class III dental relationship associated to a complete maxillary edentulism, partial edentulism of the mandible, enlarged wide and flat tongue, transverse discrepancy between a normal maxilla and an enlarged mandible noticed by the position of the displaced anterior lower teeth (Fig. 1). Radiographical features corroborated clinical findings, mandibular dentoalveolar protrusion with overangulation of inferior teeth, decreased oropha- 
ryngeal airway, overjet of $6 \mathrm{~mm}$ and atrophic maxilla and alveolar bone loss surrounding inferior teeth (Fig. 2). Speech therapist evaluation also reinforced the evidence of lip incompetence with sagging of the orbicularis oris muscle, everted lower lip, bulky and flaccid tongue with atypical swallowing. Past dental history was defined by multiple extractions without any other treatment while past medical history did not reveal any systemic disease.

The patient was diagnosed with dentofacial deformity (maxillary retraction and mandibular prognathism with transverse increase) associated with true macroglossia (enlarged tongue with negative repercussion on lower teeth, functional impairment) [5]. Indication for orthognathic surgery without previous orthodontic treatment was according to the Index of Orthognathic Functional Treatment Need (IOFTN) [9], in which the case was at grade 5 due to a reverse overjet over 3 $\mathrm{mm}$ (grade 5.3) associated with the skeletal anomaly with occlusal disturbance as a result of a pathology, i.e. macroglossia (grade 5.7).

\subsection{Proposed Treatment Plan}

Thus, proposed surgical treatment was composed of partial glossectomy associated with mandibular constriction and bimaxillary orthognathic surgery. Prior to the surgical procedure, Erich's bars were installed both on remaining lower teeth as in an upper jaw prosthesis, thus allowing model surgery to be done and an interocclusal reference to be used during surgery. No previous orthodontic treatment was deemed necessary previously to surgery since model surgery assessment revealed adequate dental occlusion to be achieved after mandibular midline osteotomy for mandibular constriction. The patient was submitted to a cephalometric analysis and predictive $2 \mathrm{D}$ tracing, and model surgery was performed based on the best occlusion with the upper jaw prosthesis as well as reduction of the mandibular perimeter by $10 \mathrm{~mm}$ (Fig. 3).

Partial glossectomy technique was performed to reduce the anterior portion of the tongue (Fig. 4). Median step osteotomy allowed mandibular constriction of $10 \mathrm{~mm}$, which was fixed with a 2.0 basal plate and a 1.5 plate on the alveolar region (Fig. 5). The other planned orthognathic procedures, Le Fort 1 osteotomy and bilateral sagittal split osteotomy, were accomplished as planned, uneventfully (Fig. 6) [10].

After about a year of follow-up, the patient demonstrated adequate lip seal (Fig. 7), patent nasal breathing, preservation of tongue protrusion and lateral movements, minor glossoplegia for superior movements with interposition of some phonemes and reported absence of taste alterations. Functional assessment was based on subjective features of preserved tongue sensations, patient's perception of better tongue mobility during speech and swallowing, and on objective findings of tongue mobility and stability of skeletal surgical movements. (Fig. 8).

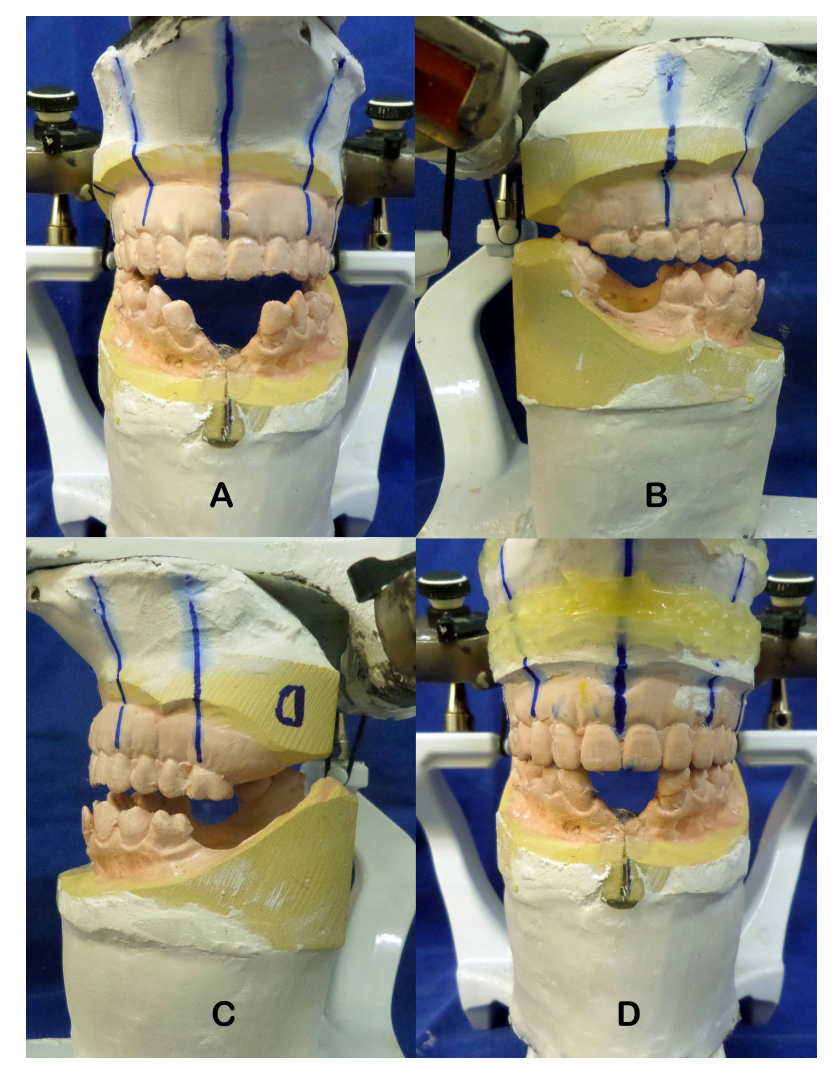

Fig. (3). Model surgery with intermediate occlusion after mandibular constriction and bilateral sagittal split osteotomies: A - Frontal view; B - Lateral right view; C - Lateral left view and with final occlusion after maxillary advancement D - Frontal view. 


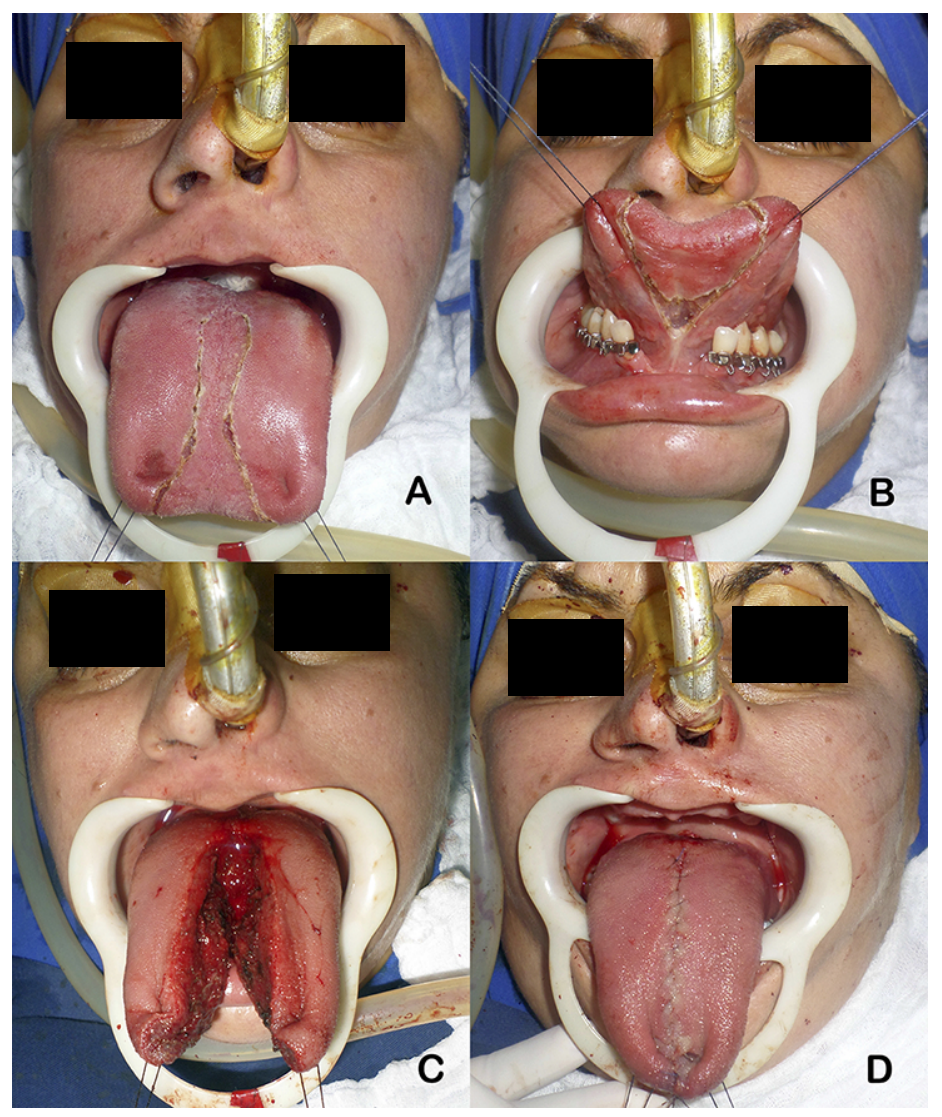

Fig. (4). Partial glossectomy dorsal (A) and ventral (B) design of incisions; After removal of midline tissues with two lateral pedicles (C); and its final aspect (D).

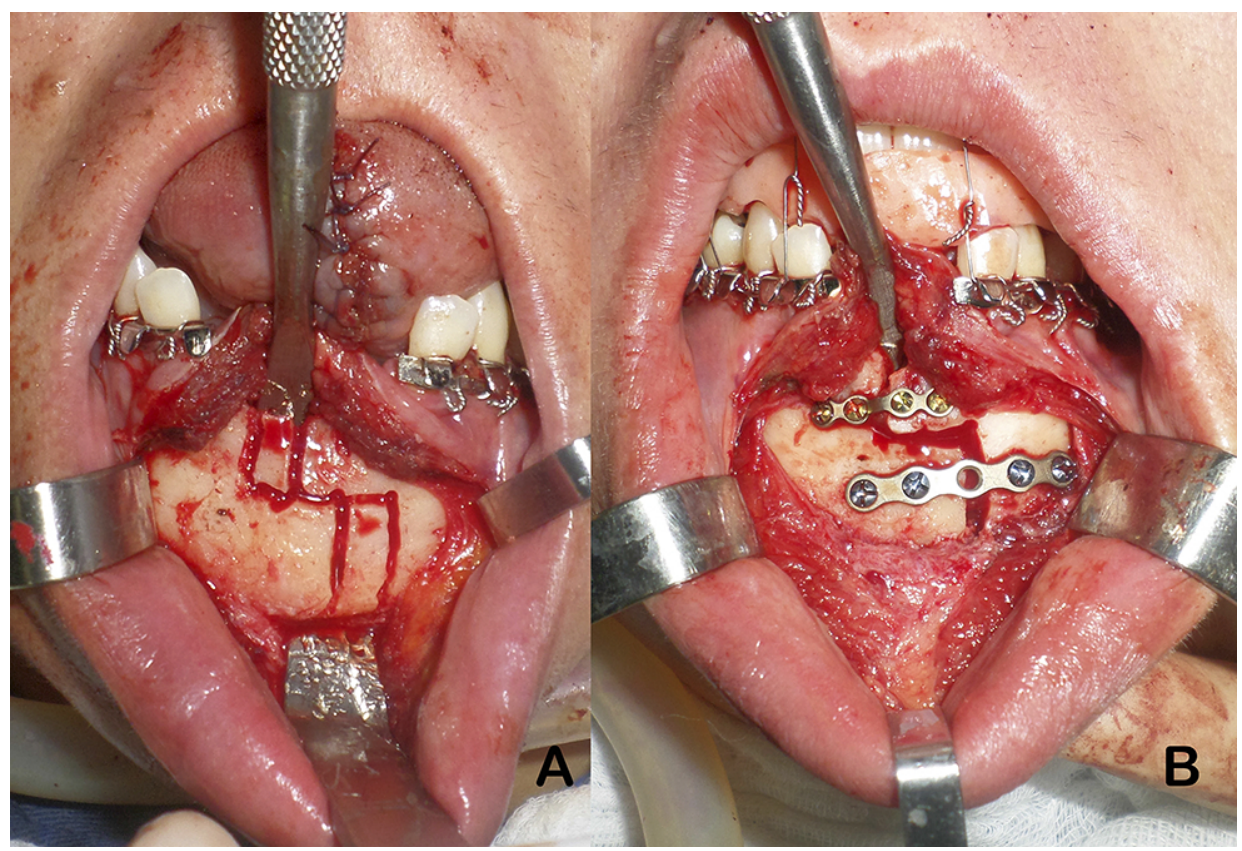

Fig. (5). Mandibular midline step osteotomy design (A) and after fixation (B). 


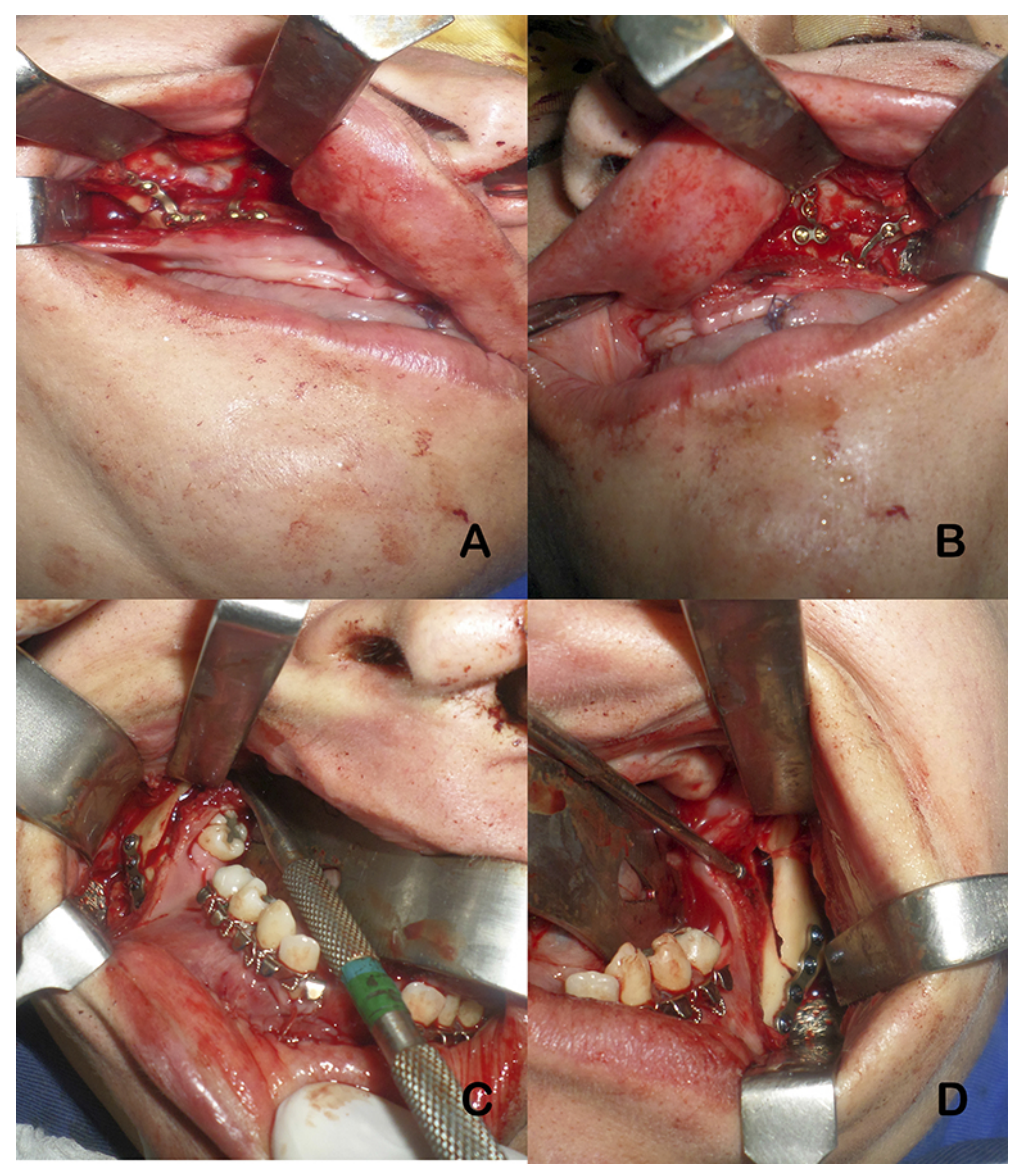

Fig. (6). Fixation of Le Fort I osteotomy of the maxilla on its right (A) and left side (B); fixation of the bilateral sagittal split osteotomies at the mandible on its right $(\mathbf{C})$ and left side (D).

The case hereby presented was elaborated accordingly to CARE statement (http://www.care-statement.org), the patient has agreed and signed a consent form authorizing publication of treatment images in the medical literature in print and online versions and all data has been treated accordingly to the Declaration of Helsinki.

\section{DISCUSSION}

Mandibular constriction performed through medial osteotomy at the symphysis, as performed in the case hereby presented, is a good alternative in cases of absolute transverse overgrowth of the maxilla, offering good postoperative stability, without the need of previous outpatient procedures while presenting low cost and low morbidity [2,8]. As graded by the IOFTN as a case of very great need for treatment [7], the patient could not be successfully managed by other means to correct the maxilla-mandibular discrepancy other than the orthognathic surgical intervention, as already expected to individuals with Class III malocclusion/sagittal skeletal pattern and with grade 5 IOFTN scores [11 - 13]. Surgery without adjuvant orthodontic treatment was indicated due to the edentulous maxilla, lack of adequate dental anchorage on the lower arch, vertical alveolar bone loss on the lower teeth and patient's will to have a shorter treatment period.

Joondeph and Bloomquist did not observe any significant relapse from the canines and the first molars while a mean relapse of $0.6 \mathrm{~mm}$ was seen transversely in the second molars in a five years follow-up, with no functional differences when comparing patients submitted to mandibular advancement associated with mandibular constriction compared to individuals submitted only to mandibular advancement. Articular changes to the temporomandibular joint were not observed or seemed to be minimal when the transversal constriction was limited to $10 \mathrm{~mm}$ [3].

Midline osteotomies of the mandible, initially developed for access to lower airways and/or tumors removal in the head and neck region, have long been performed linearly at the mandibular symphysis. Over time, it has been effectively used for mandibular constrictions, but occasional non-union or periodontal defects have been observed. In view of these postoperative complications, the step osteotomy arose as an option to present a greater area of bone contact, consequently with more stability and less chance of postoperative periodontal defects [4].

Indications for performing partial glossectomy are rare. The patient with true macroglossia presented evident clinical and cephalometric characteristics such as mandibular prognathism and lip incompetence, so proper identification of signs and symptoms are paramount to diagnosis and to determine if the tongue reduction is indicated solely or if additional procedures such as orthognathic surgery and mandibular constriction will be needed to correct skeletal deformities [5]. 


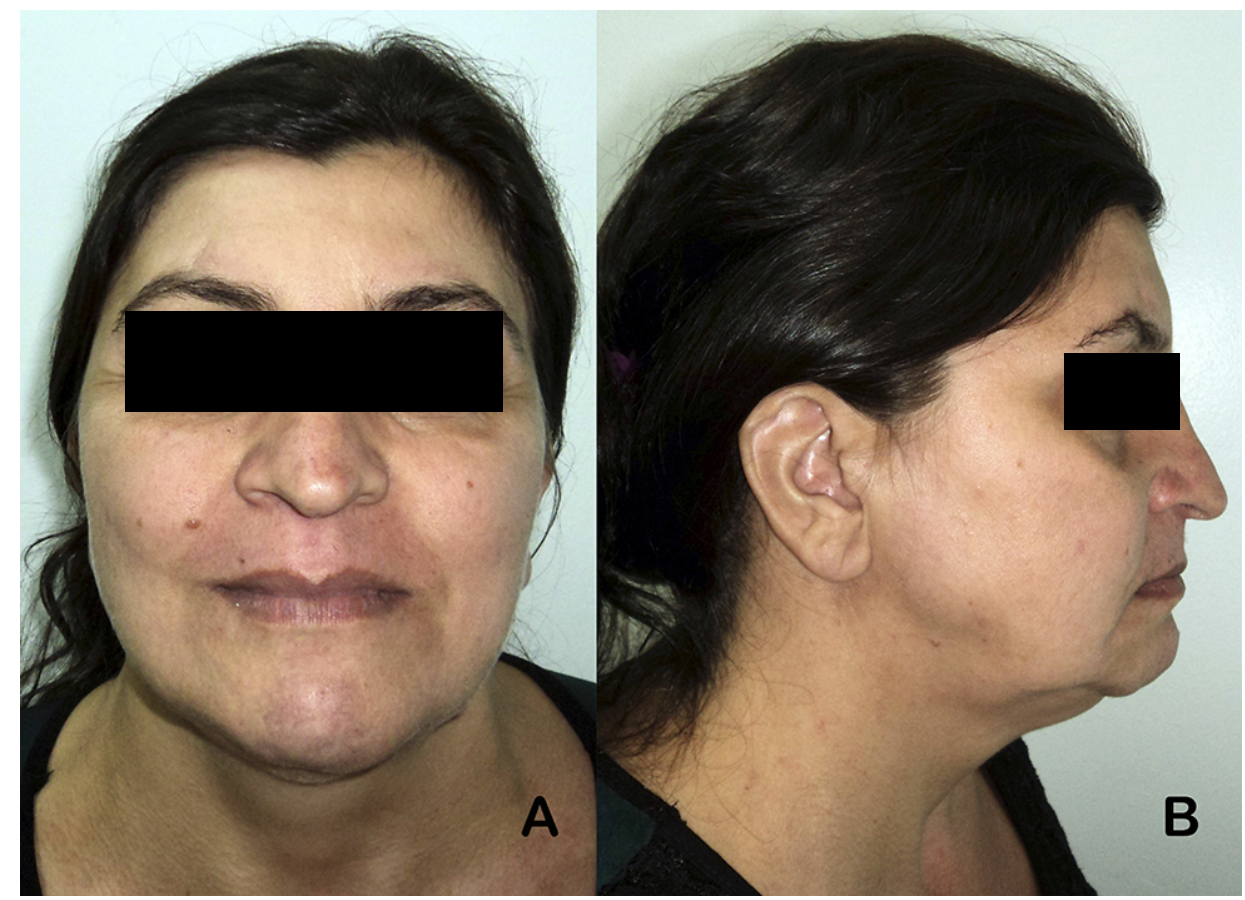

Fig. (7). Facial aspect after surgery, 13 months follow-up.

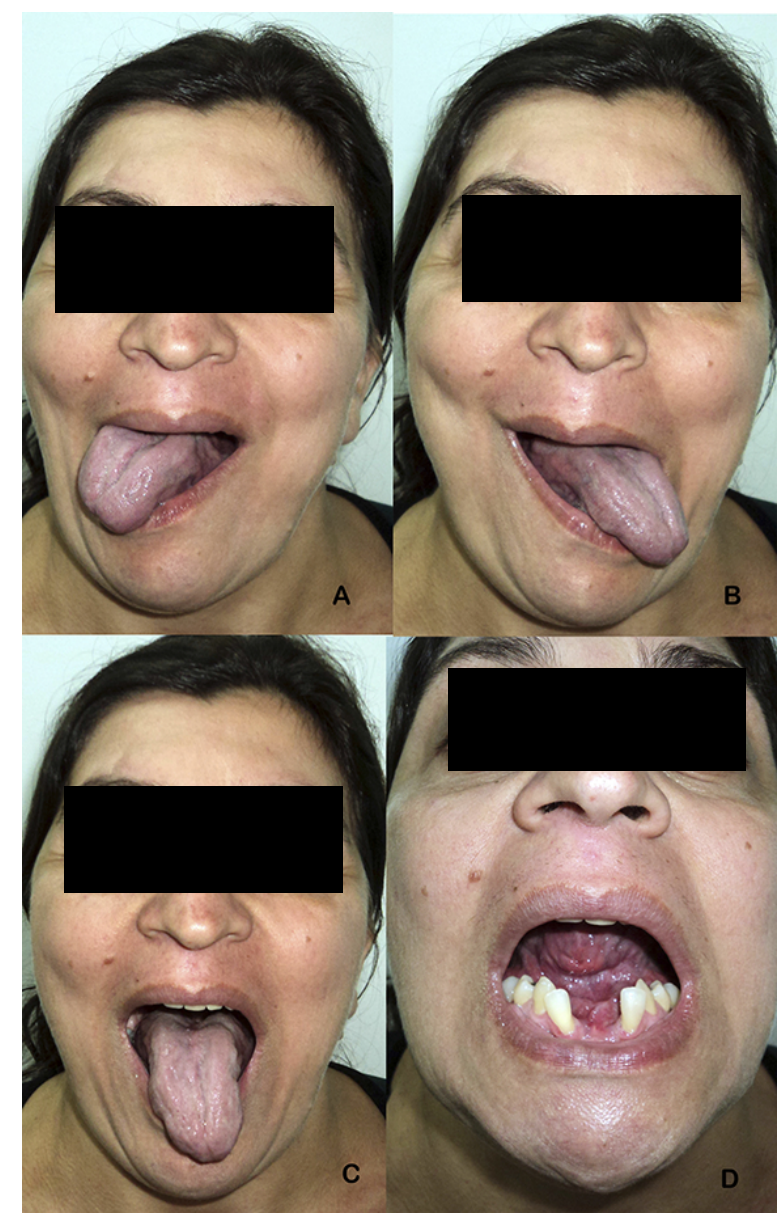

Fig. (8). Post-surgical tongue movements to the right (A), left (B), downwards (C) and upwards (D). 
In a case with true macroglossia when mandibular setback is required, the chances of relapse are greater if partial glossectomy is not performed. Due to the concern of airway obstruction and the need for Intermaxillary Fixation (IMF), many cases have been treated in two separated surgical interventions. However, current osteosynthesis materials, virtual surgical prediction and the understanding of the upper airway repercussion in the immediate postoperative provide more safety to the overall treatment in a single surgical procedure [8].

Treatment of true macroglossia usually requires tongue reduction in all dimensions, so techniques performed along the midline and lingual apex are more effective. However, limited and delicate manipulation is important to preserve noble structures, especially hypoglossal nerve endings - the main motor innervation of the tongue. Motor limitations usually occur in lifting movements while lateral and protrusive movements are preserved in most cases. Sensory changes, when noted, are usually small and reversed by the remaining neural ramifications. Despite the rare possibility of necrosis of the tongue remnant due to the involvement of the lateral vascular supply and its anastomoses, vascular preservation is also extremely important [6].

Airway obstruction secondary to tongue edema is one of the major postoperative concerns, but since immediate IMF has become rare, management of upper airway has become faster and safer [5]. Potential complications following partial glossectomy also include hemorrhage, paresthesia, and loss of taste, partial glossoplegia, scar contraction, salivary duct injury, and dysphonia. Adequate surgical technique and careful postoperative follow-up are essential to avoid any of possible complications. Indeed, it is during the postoperative period that speech-language therapies become essential for the reestablishment of speech, swallowing, and tongue movements. Due to the musculoskeletal changes performed by orthognathic surgery and mandibular constriction, such therapies are also important to restore the amplitude and balance of the mandibular movements [14].

\section{CONCLUSION}

Multiple problems may require multiple procedures, if possible, simultaneously. The case hereby presented illustrates how orthognathic surgery was able to correct anteroposterior discrepancy, concomitant mandibular midline osteotomy provided constriction of mandibular width and partial glossectomy to correct a true macroglossia. In spite of the complexity of surgical intervention, functional improvement together with an aesthetical improvement was achieved.

\section{ETHICS APPROVAL AND CONSENT TO PARTICI- PATE}

The case hereby presented was elaborated accordingly to CARE statement (http://www.care-statement.org). Ethical approval was obtained from the IRB committee of the University of Cuiaba as part of a greater project entitled "Evaluation of the accuracy of orthognathic surgery in the management of dentofacial deformities" (approval number 1.169.136).

\section{HUMAN AND ANIMAL RIGHTS}

No animals were used for studies that are the basis of this research. All research procedures followed were in accordance with the Helsinki Declaration of 1975, as revised in 2013.

\section{CONSENT FOR PUBLICATION}

Written informed consent was obtained from the patient for publication of this case report, including accompanying images.

\section{CONFLICT OF INTEREST}

The authors declare no conflict of interest, financial or otherwise.

\section{ACKNOWLEDGEMENTS}

Declared none.

\section{REFERENCES}

[1] Khechoyan DY. Orthognathic surgery: General considerations. Semin Plast Surg 2013; 27(3): 133-6.

[http://dx.doi.org/10.1055/s-0033-1357109] [PMID: 24872758]

[2] Anghinoni ML, Magri AS, Di Blasio A, Toma L, Sesenna E. Midline mandibular osteotomy in an asymmetric patient. Angle Orthod 2009; 79(5): 1008-14

[http://dx.doi.org/10.2319/102908-550.1] [PMID: 19705948]

[3] Joondeph DR, Bloomquist D. Mandibular midline osteotomy for constriction. Am J Orthod Dentofacial Orthop 2004; 126(3): 268-70. [http://dx.doi.org/10.1016/j.ajodo.2004.06.027] [PMID: 15356482]

[4] Clayman GL, Adams GL. Modifications of the mandibular swing for preservation of occlusion and function. Head Neck 1991; 13(2): 102-6. [http://dx.doi.org/10.1002/hed.2880130204] [PMID: 2022473]

[5] Wolford LM, Cottrell DA. Diagnosis of macroglossia and indications for reduction glossectomy. Am J Orthod Dentofacial Orthop 1996; 110(2): 170-7.

[http://dx.doi.org/10.1016/S0889-5406(96)70105-1] [PMID: 8760843]

[6] Balaji SM. Reduction glossectomy for large tongues. Ann Maxillofac Surg 2013; 3(2): 167-72.

[http://dx.doi.org/10.4103/2231-0746.119230] [PMID: 24205477]

[7] Bergman RT. Cephalometric soft tissue facial analysis. Am J Orthod Dentofacial Orthop 1999; 116(4): 373-89.

[http://dx.doi.org/10.1016/S0889-5406(99)70222-2] [PMID: 105116 65]

[8] Bergman RT, Waschak J, Borzabadi-Farahani A, Murphy NC Longitudinal study of cephalometric soft tissue profile traits between the ages of 6 and 18 years. Angle Orthod 2014; 84(1): 48-55. [http://dx.doi.org/10.2319/041513-291.1] [PMID: 23834271]

[9] Ireland AJ, Cunningham SJ, Petrie A, et al. An index of orthognathic functional treatment need (IOFTN). J Orthod 2014; 41(2): 77-83. [http://dx.doi.org/10.1179/1465313314Y.0000000100] [PMID: 2495 1095]

[10] Böckmann R, Meyns J, Dik E, Kessler P. The modifications of the sagittal ramus split osteotomy: A literature review. Plast Reconstr Surg Glob Open 2015; 2(12): e271.

[http://dx.doi.org/10.1097/GOX.0000000000000127] [PMID: 2558 7505]

[11] Jung Y-W, On S-W, Chung K-R, Song S-I. Simultaneous Glossectomy with Orthognathic Surgery for Mandibular Prognathism. Maxillofac Plast Reconstr Surg 2014; 36(5): 214-8.

[http://dx.doi.org/10.14402/jkamprs.2014.36.5.214] [PMID: 2748 9836]

[12] Borzabadi-Farahani A, Eslamipour F, Shahmoradi M. Functional needs of subjects with dentofacial deformities: A study using the Index of Orthognathic Functional Treatment Need (IOFTN). J Plast Reconstr Aesthet Surg 2016; 69(6): 796-801. 
[http://dx.doi.org/10.1016/j.bjps.2016.03.008] [PMID: 27068664]

[13] Harrington C, Gallagher JR, Borzabadi-Farahani A. A retrospective analysis of dentofacial deformities and orthognathic surgeries using the Index of Orthognathic Functional Treatment Need (IOFTN). Int J Pediatr Otorhinolaryngol 2015; 79(7): 1063-6. [http://dx.doi.org/10.1016/j.ijporl.2015.04.027] [PMID: 25957779]

[14] Bachher GK, Dholam K, Pai PS. Effective rehabilitation after partial glossectomy. Indian J Otolaryngol Head Neck Surg 2002; 54(1): $39-43$.

[http://dx.doi.org/10.1007/BF02911004] [PMID: 23119850]

\section{(C) 2019 de Araujo Filho et al.}

This is an open access article distributed under the terms of the Creative Commons Attribution 4.0 International Public License (CC-BY 4.0), a copy of which is available at: (https://creativecommons.org/licenses/by/4.0/legalcode). This license permits unrestricted use, distribution, and reproduction in any medium, provided the original author and source are credited. 